\title{
Desgarro esofágico espontáneo extenso con hemorragia digestiva alta tratado con la aplicación de un endoclip
}

\author{
M. Areia, P. Amaro, P. Figueiredo, F. Portela, M. Ferreira, A. Rosa, J. M. Romãozinho, \\ H. Gouveia y D. Freitas
}

Departamento de Gastroenterología. Hospital Universitario de Coimbra. Coimbra, Portugal

\section{INTRODUCCIÓN}

Los desgarros esofágicos espontáneos son una causa rara de hemorragias digestivas altas que se producen normalmente después del vómito o las arcadas y sin instrumentación ni traumatismo previos (1). Si afectan a la unión gastroesofágica o al cardias se llaman síndrome de Mallory-Weiss.

\section{CASO CLÍNICO}

Un varón de 61 años presentó emesis tras algunos episodios de arcadas. Tenía cirrosis hepática pero sin hemorragias previas. Una endoscopia alta reveló un desgarro amplio de $10 \mathrm{~cm}$ que afectaba a la mucosa y la submucosa del esófago distal, respetando un segmento de $2 \mathrm{~cm}$ de largo proximal a la línea Z (Fig. 1). La laceración presentaba una hemorragia rezumante lenta que se detuvo con la inyección de $6 \mathrm{cc}$ de adrenalina al 1:10000 y la aplicación de 17 endoclips para cerrar la laceración. La recurrencia de la hemorragia 8 días después se controló con la aplicación de otros 4 endoclips. No hubo ninguna otra recurrencia hemorrágica y se repitió la endoscopia en la semana 6 (Fig. 2) y la semana 24, no observándose lesión alguna.

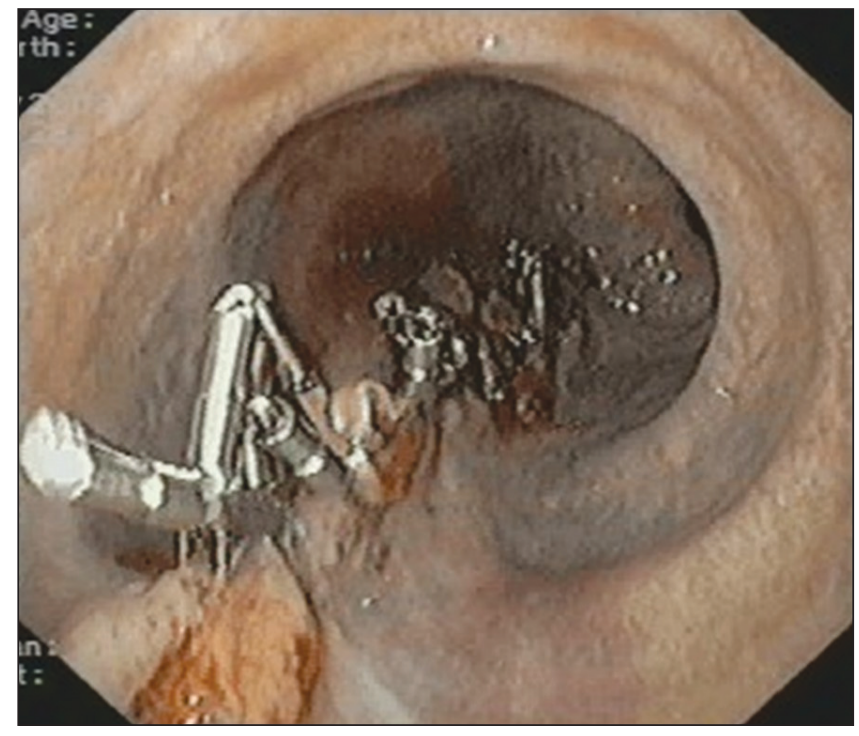

Fig. 1. Vista endoscópica que muestra un amplio desgarro esofágico de $10 \mathrm{~cm}$, cerrado con la aplicación de 17 endoclips.

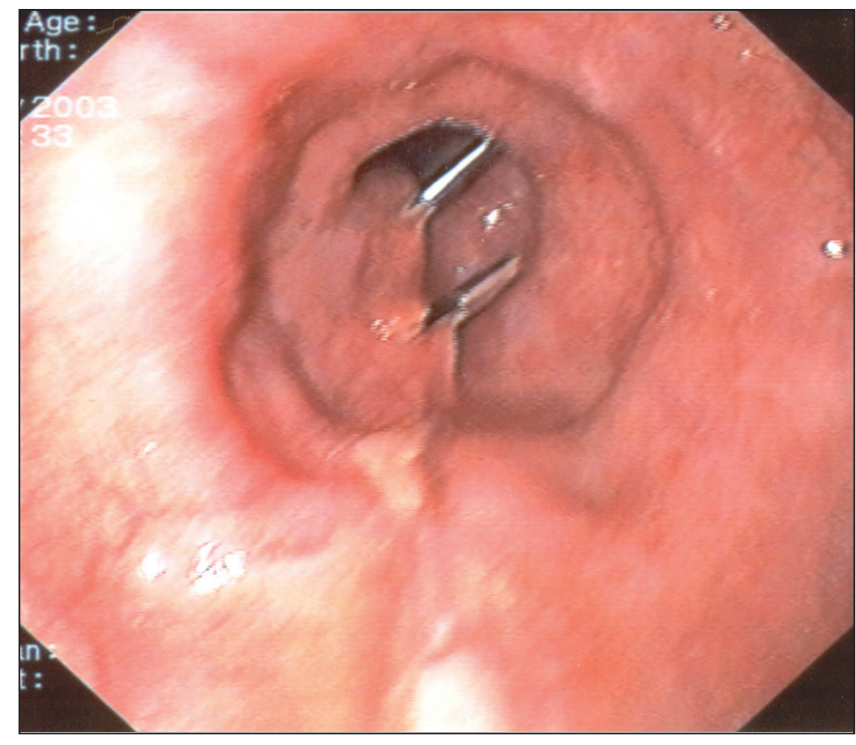

Fig. 2. Vista endoscópica en la semana 6, que muestra la cicatriz esofágica con 2 endoclips todavía. 


\section{DISCUSIÓN}

Los endoclips son una técnica endoscópica bien conocida para el control de la hemorragia digestiva, usándose en las úlceras pépticas, las lesiones de Dieulafoy, los desgarros de Mallory-Weiss y la hemorragia diverticular o post-polipectomía, y también en otras situaciones, como el cierre de laceraciones (2), perforaciones, fístulas y fugas anastomóticas, y el anclaje de sondas, catéteres y stents, o simplemente como marcadores fluoroscópicos (3). Su efectividad y seguridad en pacientes con hemorragia digestiva por síndrome de Mallory-Weiss fue abordada por Yamaguchi Y y cols. en un estudio de 26 sujetos (4). Se logró el éxito técnico en el 100\%, con una media de 2,8 endoclips por paciente y con ausencia de complicaciones, hemorragias recurrentes y muertes. Los endoclips no produjeron lesiones tisulares, ni retrasaron la cicatrización. De hecho, parecen potenciar el proceso de cicatrización, además de ejercer su función hemostática, como parece haber ocurrido en nuestro paciente. En los desgarros amplios como el descrito, incluso en presencia de hemorragia, el empleo de endoclips parece ser una técnica endoscópica buena y efectiva siempre que la laceración no afecte a todas las capas de la pared esofágica.

\section{BIBLIOGRAFÍA}

1. Younes Z, Johnson DA. The spectrum of spontaneous and iatrogenic esophageal injury: perforations, Mallory-Weiss tears, and hematomas. J Clin Gastroenterol 1999; 29 (4): 306-17.

2. Gölder SK. Traumatic incomplete rupture of the gastric wall: endoscopic treatment with clip application. Endoscopy $2005 ; 37$ (5): 497.

3. Raju GS, Gajula L. Endoclips for GI endoscopy. Gastrointest Endosc 2004; 59 (2): 267-79.

4. Yamaguchi Y, Yamato T, Katsumi N, Morozumi K, Abe T, Ishida H, et al. Endoscopic hemoclipping for upper GI bleeding due to Mallory-Weiss syndrome. Gastrointest Endosc 2001; 53 (4): 427-30. 